\title{
DIE MORFOLOGIE VAN DIE NAAMWOORDELIKE WOORDSOORTE IN NOORD-SOTHO
}

In die vorige artikel (Koers, Junie 1958) het ons melding gemaak van die probleem van woordsoorindeling en hoe dit die Bantoetale raak. In hierdie artikel wil ons graag ' $n$ beskrywing gee van die morfologiese struktuur van die naamwoord. Die naamwoordelike woordsoorte bestaan uit Naamwoorde en Voornaamwoonde van verskeie soorte. Die naamwoorde verdeel ons in drie tipes, al na gelang van die konkordiale invloed wat elk van hulle uitoefen in die sinstruktuur. Onder bespreking kom net een van hierdie drie soorte, t.w. naamwoorde wat konkordiale invloed uitoefen in die sin. (vgl. bls. 384 in „Koers" Junie 1958).

\section{KONKORDIAAL-BEYNVLOEDENDE NAAMWOORDE OF EGTE NAAM- WOORDE:}

Die woord "egte" beteken hier "wat konkordiale invloed uitoefen. D.w.s. die „skakels" en voornaamwoorde van hierdie naamwoorde is funksioneel aktief en dien die doel waarvoor hulle geskep is. Hulle vorm die oorgrote meerderheid en is afkomstig uit die sogenaamde ,lewende klasse van selfstandige naamwoorde. Ons wil egter eers 'n uiteensetting gee van wat met
Naamwoordklasse bedoel word, maar ons gaan wysgerige, sielkundige redenasies oor die oorsprong, wese en semantiese inhoud van elk van hierdie klasse van naamwoorde vermy. Dis interessant maar taalkundig van nul en gener waarde.

Soos ons hieronder sal waarneem, word die naamwoorde van Bantoetale in klasse of soorte ingedeel. Elke naamwoordklas word gekenmerk deur twee prefikse, een vir die enkelvoud bv. moin die woord motho en ba- in die woord batho (mens, mense resp.) Die aantal klasse wissel van taal tot taal. Een klas van naamwoorde bevat dus enkelvoud en meervoud, maar vir taalwetenskaplike doeleindes word enkelvoud en meervoud as aparte klasse gereken.

Die morfologiese struktuur van die naamwoord is soos volg: prefigale morfeem + logeem ( + suffix en/of uitgang). Die basiese fonetiese struktuur van die prefigale morfeem is in die Bantoetale soos volg: (v) $+\mathrm{k}+\mathrm{v}$. In Zulu bv. is die basiese struktuur soos volg: $\mathbf{v}+\mathbf{k}+\mathbf{v}$, maar in die Sothotale is dit $\mathbf{v}+\mathbf{k}$. Die prefikse is baie maal aan modifikasies of veranderinge onderhewig, dog dit is altyd fonologies verklaarbaar. Hierdie gemodifieerde va- 
riante noem ons morfemiese variante of allomorfeme of sub-prefikse. Verder is die klasprefikse van groot belang by die vorming van die naamwoorde en "skakels" soos ons later sal opmerk. (Die Bantoe kan bv. nie 'n leenwoord gebruik in sy taal voordat dit nie eers in 'n spesifieke klas geplaas is nie, want anders weet hy nie watter ,skakel" of voornaamwoord hy daarby moet gebruik nie.) Semanties kan hierdie naamwoordklasse nie in waterdigte kompartemente ingedeel word nie. Daar bestaan net algemene aanduidings. Aangesien ons hier met morfologie te doen het, laat ons die semantiese buite beskouing.

\section{DIE PREFIGALE MORFEME VAN DIE NAAMWOORD:}

Daar bestaan net een soort prefigale morfeem en sluit die stam oî logeem af vir verdere prefigering. Hulle maak die sogenaamde klasprefikse uit. Die basiese vorm van die klasprefiks word eerste genoem en daarna die subprefikse of allomorfeme. Hulle kom nie baie voor nie, hoogstens by 'n paar woorde in elke geval, behalwe by die ne-di-klasse (klasse 9 en 10). (Die klasse word genumeer volgens Bleek en Meinhof.)

\section{Klas I:}

a. mo-: Enkelvoud. Motho mens; Mohumi ryke; mokgalabjê ouman; monna man; mosadi vrou; modiri arbeider, werker.

b. m- - : Allomorf, voor logeme wat met bilabiale stemhebbende eksplosief of frikatief b- begin: mmolêdi mo-bolêdi, spreker; mmusi mo-busi, regeerder; mmadi mo-badi, teller leser; mmêtli mobêtli, skrynwerker, beeldhouer. Die fonologiese prosesse wat daarvoor verantwoordelik is, is elisie (van die - $0_{-}^{-}$) en progressiewe assimilasie.

c. ngw-: Allomorf voor logeme wat met die vokaalfoneme -a-, -e-, begin. Ngwana mo-ana, kind; ngwetsi mo-etsi, skoondogter; ngwale mo-ale, stamskoolmeidjie. Dis te wyte aan velarisasie, of ook palatalisasie. Labialisasie speel ook 'n rol. Dit geld egter nie wanneer die naamwoord ' $n$ Deverbatief is nie. Bv. moalafi, geneesheer; moeti, reisiger.

d. - - : Zeromorfeem. Tate vader; mmê moeder; malome oom aan moederskant; rakgadi tante aan vaderskant; mmane tante aan moederskant.

Klas 2.

a. ba - : Meervoud vir klas I. Batho, bahumi, bakgalabje, banna, basadi, badiri. Maar babolêdi (mobolêdi, mmolêdi); babusi; (mobusi, mmusi) ens.

b. b- : Allomorf voor logeme wat met 'n vokaalfoneem begin (vgl. klas I.c.). Bana (moana, ngwana); bale mo-ale ngwale); betsi (moetsi, ngwetsi).

c. bô- : Meervoud vir Zero hierbo. Botate, bommê, bômalome, bôrangwane, bôrakgadi, bômmane.

Klas 3.

a. mo - : Enkelvoud. Modirô, werk, arbeid; morula, morulaboom; mosito, geluid; mollô, vuur; mokô kôtlô rug.

b. M- - : Allomorf voor stamme wat met die bilabiale, eksplosief of frika- 
tief - b - begin. Mmusô (mobusô), regering, mmolêlô (mobolêlô), spraak, spreekwyse; taal; mmutla (mo-butla), haas; mmolaô (mobolaô), moord.

c. ngw- : Allomorf voor logeme wat met 'n vokaalfoneem begin. $\mathbf{N g w a g a}$ (mo-aga), jaar; ngwang (mo-ang), onkruid; ngwakô (mo-akô), gebou, huis, woning. Dit is ook voorbeelde van velarisasie en labialisering. Verdere voorbeelde is Ngwêdi (moêdi), maan.

d. mph.- : Alternatiewe allomorf voor logeme wat met die bilabiale stemlose frikatief - f - begin. Mofo/ mphó, geskenk; mofiri/mphiri, koperring, koper; mofikelâ/mphikêlâ, verkoue, griep; mofufutsô/mphufutsô, sweet; mofoma/mphoma, grot; mofolô/mpholô, gif.

Klas 4.

a. me- : Meervoud vir klas 3. Mêdirô, merula, mesitô, mellô, mekokotlo. N.B. Meervoud vir Klas 3.b. is soos volg: Mebusô (mobusô, mmuso); mebutla (mobutla, mmutla) ens.

b. nyw-: Alternatiewe allomorf voor stamme wat met vokaalfoneem begin. Ngwako, mengwako/nywakỏ; Ngwaga, mengwaga/nywaga. Die proses daarvoor verantwoordelik is palatalisering.

Klas 5.

a. le- : Enkelvoud. Lefsêga, lafaard; letlakala, tak; lerumô, assegaai; lekgowa, blanke; Lethosa, Xhosa.

b.- - : Zeromorfeem. 'lapa, werf; 'gae, tuiste; 'naka, horing. Veral 'n kenmerk van Suid-Sotho.
Klas 6

a. ma- : Meervoud vir Klas 5. Mafsêga; matlakala; marumó, Makgowa. 'n Aantal Selfstandigenaamwoorde in hierdie klas kom net in die meervoud voor: maatla, krag; madi, bloed; mare, speeksel, meetse (maetse), water; marega, winter; mabêlê, koring; mafura, vet; mafsi, melk ;

b. m- : Allomorf voor vokaalfoneem. Matla (ma-atla); madi (ma-adi).

Klas 7:

se-: Enkelvoud. Sejô (kos) ; sediba (fontein); seboledi (spreker).

Klas 8.

a. di- : Meervoud vir Klas 7: Dijô, dibolêdi, dibolai, ens. Vir Klasse 8 en 9 is daar geen allomorfeme nie.

Klas 9 .

n- - : Enkelvoud (Die oorspronklike prefigale morfeem was ni-, dog as gevolg van Nasaalversterking het klankverandering ingetree sodat die prefiks nie of in gemodifiëerde vorm sigbaar is. Die prefiks van hierdie Naamwoordklas is dus morfologies nie so maklik herkenbaar as dié van die ander klasse nie. Aangesien 'n bespreking van $h$ ierdie klanke by die fonologie tuis hoort, gee ons net die resultaat. Nku, skaap; nkwê, tier, polêlô, taal, thaba, berg; noka, rivier; mphô, present, gawe; mpsa, hond, karabo, antwoord; khumô, rykdom; kgôme, bees; tau, leeu; ens.

Klas 10.

a. di- : Meervoud vir Klas 9. Dinku, dinkwê, dipolêlô, dithaba, dinoka, ens. 
Klas 14.

a. bo- : Enkelvoud. (Klas 11, 12, 13 bestaan nie in Noord-Sotho nie.) Boh/ale, wysheid; boruthô, warmte; botse, mooiheid; bobe, slegtigheid; bogale, wreedheid.

b.- - : Allomorf voor $u / o$, bv. Bupi (bo-upi), meel.

c. bj- : Alomorf voor vokaalfoneem - a - bv. Bjalwa (bo-alwa) bier; bjalô (bo-alô) so; bjang (bo-ang) gras; bjana (bo-ana). Bjalo word nie meer as naamwoord gebruik nie.

Klas 6.

a. ma- : Meervoud vir Klas 14. (Klas 6 se meervoud word gebruik vir naamwoorde (vir Klas 14).

Klas 15.

a. go- : Enkelvoud. Geen meervoud. Godira, die werkery; goloma, die bytery; goja, die etery; goaga, die bouery, ens.

\section{SUFFIGALE MORFEME VAN DIE NAAMWOORD:}

A. Die Lokatiewe Suffigale Morfeem:

Dié morfeem se funksie is om lokaliteit uit te druk. Dit word in Afrikaans vertaal met die voorsetsels in, van, by, na, op uit. Bv. Banna ba-ya thabêng (thaba- + êng): Die manna gaan na die berg. Ditshwene di-dula thabêng. Die bobbejane woon in die berg. Ba kwa thabêng: Hulle is daar by die berg.

Soos die voorbeelde aandui bepaal die werkwoord, uit die aard van sy betekenis, met watter voorsetsel die lokatiewe vorm van die naamwoord vertaal moet word. Daar kom die volgende variante in Noord-Sotho voor:

a.-ng: Dit word aangewend by naamwoorde wat sake aandui en nie persone nie. Vgl. egter een of twee gevalle soos bathong en kgosing: by die mense, en, by die koning respektiewelik.

b. -êng: Allomorf wanneer die naamwoord -a as uitgangsvokaal het. Bv. thaba, thabêng, by, na, ens, die berg; noka nokêng, by na, ens. die rivier; tsela, tselêng, by, na, ens. die berg.

c. yêng: Allomorf wanneer naamwoord op -ng foneem eindig. Bv. lelong, lenonyêng, by die aasvoëls; bjang, bjanyêng, in, ens. die gras; kgong, kgonyêng, by die hout.

B. Die Diminutiewe Morfeem:

Hierdie morfeem het ook drie variante met klein semantiese verskille.

a. -ana: Dit dui verkleining aan in die gewone graad. 'n Variant hiervan is -anê. Bv. tsela, tselana, paadjie; kolobê kolobjana, varkie; pudi putsana, bokkie;

c. -anyana: Verdubbeling van -anê + -ana. Dui jonkheid, jeugdigheid en intensifisering aan. Bv. putsanyana jong klein bokkie; sehlare, sehlasanyana, jong klein boompie. Vgl. -anyanê.

d. -nyana: Dui verkleining en veragting aan. Bv, pudinyana, potsierlike bokkie; sehlarenyana, verkrimpte boompie.

Die suffigering van -ana en -anyana veroorsaak fonologiese veranderinge in die slotsillabe van die naam- 
woord, terwyl -nyana sonder veranderinge gesuffigeer word behalwe wanneer die naamwoord op -ng eindig. Ons noem 'n paar voorbeelde: kgarêbê + -ana, kgarebjana, meisietjie; kgogo + -ana, kgogwana, hoendertjie; nalêdi + -ana, nalêtsana, sterretjie; mmele + ana, mmejana, liggaampie; tshemo + -ana, tshengwana, landjie; selêpê $\dashv-$ -ana, selêtswana, byltjie; nare = ana, nasana,buffeltjie; nong + -ana nonyana, aasvoëltjie of voëltjie; nku + -ana, nkwana, skapie; ens.

C. Vroulike en Augmentatiewe suffigale Morfeem:

a. -gadi: Dui vroulikheid aan, bv. kgomogadi, koei; kgosigadi, koningin; mohlôlagadi weduwee, ens. Hierdie suffix word in Suid-Sotho veral as 'n augmentatiewe suffiks gebruik, bv. monnahali, baie groot man (S. Sotho-li N.Sotho -di ortografies); sefatehali, tamaai groot boom; kgomogadi, baie groot bees.

b. -gadi-gadi: Versterking van a. hierbo.

c. -adi-: Allomorf, bv. morwadi, dogter morwa, seun;

d. -gatsana: Allomorf, weinig gebruik soos b. en c. Dis 'n samestelling van -gadi en -die diminutief -ana, bv. kgomogatsana, koeitjie.

D. UITGANGSMORFEME:

a. -i: Uitgangsmorfeem van naamwoord wanneer van ww. afgelei. Bv. dira, modiri, arbeider; aga, moagi, bouer; ngwala, mongwadi, skrywer; ens. Dit dui die persoon wat die handeling verrig aan.

b. ô: Uitgangsmorfeem by Deverba- P.U. vir C.H.O. tiewe om sake aan te dui. Dit dui dus aan die aard van die handeling, die resultaat van die handeling of die eienskap in die handeling vervat aan. Bv. dira, modirô, die werk; aga, moagô, gebou; ngwala, mongwalô, skryfwyse, styl, ens.

c. -a: Die werkwoord kan die -a uitgang behou en dien dus as variant van a. hierbo. Dis veral by passiewe die geval. Bv, dira modira; werker; disa modisa, wagter; rongwa morongwa, engel; ahlolwa moahlolwa, beskuldigde; ens.

d. -e: Uitgangsmorfeem by Deverbatiewe in weinige gevalle. Bv. bôna, sien, lebône, lig, lamp; hlatsa, getuig, bohlatse, getuienis; opêla, sing, meopêlane, triomfgesange; bola, verrot, sebodu, luiaard, vrotterd; ens.

Die naamwoordklasse in Bantoetale is die basis waarop die hele sinstruktuur berus. Dit is aan een van die mees karakteristieke eienskappe wat alle Bantoetale in Afrika in gemeen het, alhoewel die struktuur van die prefiks nie dieselfde is nie. Hulle is egter almal herleibaar tot 'n gemeenskaplike oorsprong. Uit hierdie klasprefikse word alle skakels en voornaamwoorde afgelei, soos later verduidelik sal word.

Die allomorfeme (klas prefiks-variante) kom slegs by 'n paar woorde voor, en wanneer ons van die verskeie klasse praat, word hulle nie genoem nie. Kortweg praat ons van die mo-ba-klas, die mo-me-klas, die le-ma-klas, die se-diklas, die n-di-klas, die bo-ma-klas en die go-klas van selfstandige naamwoorde.

C. J. H. KRUGER. 